\title{
Prescribing habits for upper respiratory tract infections in children
}

Abbott S, MBBCh, FC Paeds(SA), MMed, Dip Allerg(SA) Paediatric Pulmonology Fellow, Department of Paediatrics, University of Pretoria Correspondence to: Salome Abbott, e-mail: salome.abbott@gmail.com Keywords: upper respiratory tract infections, children

(P) Peer reviewed. (Submitted: 2012-02-09. Accepted: 2012-07-23.) ๑ Medpharm

S Afr Fam Pract 2012;54(5):379-381

\section{Introduction}

Children with upper respiratory tract infections are commonly encountered in general practice. Most respiratory infections, including acute otitis media, a sore throat and sinusitis, are self-limiting, and symptomatic treatment is usually adequate. Despite this, upper respiratory tract infection may still be problematic owing to inappropriate use of corticosteroids, over-the-counter medicines and antibiotics in an attempt to prevent secondary bacterial infection. ${ }^{1}$ This increases the burden of antibiotic resistance and causes unnecessary side-effects for the patient. Usually, little benefit is obtained as the course of the disease is not altered. The South African guideline for the management of upper respiratory tract infections has made recommendations based on appropriate pathogens and relevant publications. ${ }^{2}$

\section{Acute rhinopharyngitis}

This is the most common type of upper respiratory tract infection. Almost all colds are caused by viruses, such as rhinovirus. Influenza virus causes influenza rather than the common cold. Respiratory syncytial virus is also not a common cause of colds. The treatment is symptomatic. A runny nose with a coloured discharge (acute purulent rhinitis) is often associated with the common cold. Primary care physicians are far more likely to prescribe an antibiotic for a cold to a patient with a purulent discharge than to one with a clear discharge. ${ }^{1}$ However, this does not necessarily signify a bacterial aetiology and is therefore not an indication for antibacterial treatment. ${ }^{1}$ Antihistamines and corticosteroids (oral and topical) do not have a role to play. Noninfectious causes of rhinorrhoea, such as allergic rhinitis or asthma, should also be considered if the symptoms are recurrent or chronic in nature.

\section{Sore throat and acute pharyngotonsillitis}

Acute pharyngotonsillitits is usually self-limiting and patients recover quickly, after three or four days, without treatment. Infections are caused by respiratory viruses predominantly. Bacteria, especially group A $\beta$-haemolytic streptococci, account for $5-30 \%$ of cases. Traditionally doctors have attempted to decide clinically whether the cause is bacterial, but deciding on the aetiological agent is difficult. Treating a sore throat with an antibiotic does not significantly shorten the duration of illness. ${ }^{3}$ However, antibiotics are still recommended to treat acute pharyngotonsillitis. This is to prevent poststreptococcal sequelae, such as acute rheumatic fever and glomerulonephritis. ${ }^{2}$

\section{Penicillin}

The treatment of choice is penicillin. ${ }^{2}$ A 10-day course is still recommended. Intramuscular injections are preferable if compliance is unlikely. Antibiotic recommendations for the treatment of acute pharyngotonsillitis are provided in Table I.

Table l: Antibiotic recommendations for acute pharyngotonsillitis

- Penicillin VK

$250 \mathrm{mg}$ twice a day for 10 days $(<27 \mathrm{~kg})$

$500 \mathrm{mg}$ twice a day for 10 days (>27 kg)

- Benzathine penicillin (intramuscular injection) $600000 \mathrm{IU}$ (3-5 years)

$1.2 \mathrm{MU}(>5$ years)

\section{Amoxicillin}

Amoxicillin is an alternative to penicillin, although this suggestion is not evidence based. ${ }^{3}$ It can be given once a day. This gives it an added advantage over penicillin. Table II lists this alternative treatment option to penicillin when treating acute pharyngotonsillitis.

Table II: Alternative recommendation for acute pharyngotonsillitis

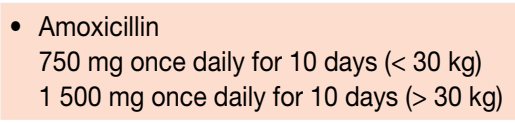

\section{Short-course therapy}

A three- to five-day course of a number of regimens is equally efficacious. This is a new development, but is also not based on evidence. Table III details short-course therapy to treat acute pharyngotonsillitis. 
Table III: Short-course therapy to treat acute pharyngotonsillitis

- Amoxicillin-clavulanate $40 \mathrm{mg} / \mathrm{kg} /$ day in three divided doses

- Azithromycin 10-20 mg/kg once daily for three days

- Clarithromycin $7.5 \mathrm{mg} / \mathrm{kg}$ twice daily

- Cefpodoxime $4 \mathrm{mg} / \mathrm{kg}$ twice daily

- Cefprozil $7.5 \mathrm{mg} / \mathrm{kg}$ twice daily

- Cefuroxime $10 \mathrm{mg} / \mathrm{kg}$ twice daily

\section{Acute otitis media}

Acute otitis media is one of the most common childhood diseases. The main bacterial pathogens are Streptococcus pneumoniae, nontypable Haemophilus influenzae and Moraxella catarrhalis. Serious complications, such as ear drum perforation, sensorineural hearing loss or the disease becoming chronic, are rare events. Most doctors prescribe an antibiotic to treat acute otitis media. However, a recent Cochrane review has shown that the number of patients needed to treat with antibiotics is 16 , in order for benefit to be obtained. ${ }^{4}$ This benefit must be weighed against the possible harms.

An expectant observational approach seems justified when treating children with mild disease. ${ }^{4} \mathrm{~A}$ reasonable strategy would be to dispense a prescription for an antibiotic and to instruct the parents to only give it if there has not been resolution after 48 hours. ${ }^{2}$ This strategy is not appropriate in the patient with limited access to health care.

An antibiotic is also essential in the following circumstances: ${ }^{2}$

- Recurrent acute otitis media

- Immunocompromised hosts

- Neonates

- Structural ear, nose and throat abnormalities

- Fever $>38^{\circ} \mathrm{C}$ or pain $>48$ hours

- Day-care attendees or siblings of day-care attendees.

The antibiotic choices are shown in Table IV. ${ }^{2}$ Most organisms are eradicated after 72 hours of antibiotics in children with acute otitis media. However, seven days of antibiotics are recommended. This eliminates pathogenic bacteria in the nasopharynx which may predispose to relapses. ${ }^{2}$ If clinical failure has occurred after 72 hours (persistent fever), referral to an otorhinolaryngologist is indicated, for tympanocentesis to be carried out and culture to be obtained.

Patients with acute otitis media who have a tympanostomy tube often show significant growth of unusual pathogens such as Pseudomonas aeruginosa and S. aureus. Topical ciprofloxacin has been shown to be efficacious, together with adequate aural toilette and the correct technique of drop insertion in this group of patients. This alleviates the need for oral antibiotics, ${ }^{5}$ except if there is disease outside the ear which needs to be treated.
Table IV: Antibiotic recommendations for acute otitis media

\section{First-line recommended therapy}

- Amoxicillin $90 \mathrm{mg} / \mathrm{kg} /$ day in three divided doses for 5-7 days

Alternative antibiotic choice

- Amoxicillin-clavulanate amoxicillin $90 \mathrm{mg} / \mathrm{kg} /$ day divided into two or three doses for 5-7 days

- Cefpodoxime proxetil 8-16 mg/kg twice daily for 5-7 days

- Cefuroxime axetil $15-30 \mathrm{mg} / \mathrm{kg}$ twice daily for 5-7 days

Antibiotics in $\beta$-lactam allergy

- Azithromycin $10 \mathrm{mg} / \mathrm{kg}$ once daily for 3 days

- Clarithromycin $7.5 \mathrm{mg}-15 \mathrm{mg} / \mathrm{kg}$ twice daily for 5-7 days

- Erythromycin $40 \mathrm{mg} / \mathrm{kg}$ twice daily for 5-7 days

- Cefpodozime proxetil 8-16 mg/kg twice daily for 5-7 days

- Cefuroxime axetil $15-30 \mathrm{mg} / \mathrm{kg}$ twice daily for 5-7 days

Failed initial therapy

- Amoxicillin-clavulanate amoxicillin as above, for initial therapy with amoxicillin

- Ceftriaxone intravenously or intramuscularly $50-75 \mathrm{mg} / \mathrm{kg}$ once daily for 3 days

\section{Acute sinusitis}

Sinusitis is one of the most common reasons to visit a doctor. In most cases, sinusitis is caused by a viral infection, so antibiotics are ineffective. Unfortunately, as with a sore throat, it is difficult to distinguish between patients who have bacterial infections and those who do not. Bacterial sinusitis is more probable if the signs and symptoms of an upper respiratory tract infection have lasted at least seven days. ${ }^{6}$ The pathogens that cause bacterial sinusitis are the same as those that are responsible for acute otitis media.

The benefit of an antibiotic is modest and does not alter the course of the disease, ${ }^{6}$ even in patients with bacterial sinusitis. However, antibiotics are often prescribed in order to prevent intracranial and extrasinus complications. Antibiotic selection should take into account previous antibiotic use as this increases the risk of carriage of resistant organisms. Chosen antibiotics should provide Gram-positive cover for S. pneumoniae and Gram-negative cover for $\mathrm{H}$. influenzae and $M$. catarrhalis. ${ }^{2}$ Antibiotic recommendations when treating acute bacterial sinusitis are listed in Table $\mathrm{V}^{2}$

There is no difference in response with varying classes of antibiotics, because most patients with sinusitis will improve without antibiotics and the margin of added clinical benefit that is gained by using them is small. It is easy to show equivalence between antibiotics. ${ }^{6}$ However, increased resistance to amoxicillin by $\beta$-lactamase production and the alteration of penicillin-binding proteins has given rise to doubt about the reliability of amoxicillin as the first-line treatment of acute bacterial sinusitis. ${ }^{11}$ If used, a high dose (90 mg/kg/day) should be prescribed. Rates of clinical success do not vary significantly for short (seven days) vs. longer-course (10-day) treatment. The recommended 10- 
Table V: Antibiotic recommendations for acute bacterial sinusitis

\section{First-line recommended therapy}

- Amoxicillin $90 \mathrm{mg} / \mathrm{kg} /$ day in three divided doses for 10 days

\section{Alternative antibiotic choice}

- Amoxicillin-clavulanate, $90 \mathrm{mg} / \mathrm{kg} /$ day total dose of amoxicillin divided into two or three doses for 10 days

- Cefpodoxime proxetil 8-16 mg/kg twice daily for 10 days

- Cefuroxime axetil $15-30 \mathrm{mg} / \mathrm{kg}$ twice daily for 10 days

Antibiotics in $\beta$-lactam allergy

- Azithromycin $10 \mathrm{mg} / \mathrm{kg}$ once daily for 3 days

- Clarithromycin $7.5 \mathrm{mg}-15 \mathrm{mg} / \mathrm{kg}$ twice daily for 10 days

- Erythromycin $40 \mathrm{mg} / \mathrm{kg}$ twice daily for 10 days

- Cefpodozime proxetil 8-16 mg/kg twice daily for 10 days

Failed initial therapy

- Amoxicillin-clavulanate, $90 \mathrm{mg} / \mathrm{kg} /$ day total dose of amoxicillin divided into two or three doses for 10 days

- Ceftriaxone intravenously or intramuscularly $50-75 \mathrm{mg} / \mathrm{kg}$ once daily for $3-5$ days

day course is not evidence based and short-course therapy is just as likely to effect a cure.

As an adjuvant to oral antibiotics, topical corticosteroids have been shown to improve symptoms, ${ }^{7-10}$ although they do not affect final outcome. However, currently, topical corticosteroids are not recommended in the South African guideline for the treatment of acute sinusitis. ${ }^{2}$ It is reasonable to consider this as an option. Patients with more severe disease or complicated sinusitis should be referred for appropriate otorhinolaryngeal opinion. Upper respiratory tract infections are one of the most common reasons why children visit the doctor. Since most of these infections are self-limiting, symptomatic treatment is usually sufficient.
Generally, antibiotics are not indicated as viral pathogens are the cause. Antibiotics should be used with caution, together with topical corticosteroids in certain circumstances. Oral corticosteroids play a very limited role. Education and reassurance of patients and parents can help to prevent inappropriate prescribing habits in the management of upper respiratory tract infections in children.

\section{References}

1. Arroll B, Kenealy T. Antibiotics for the common cold and acute purulent rhinitis. [Cochrane review]. In: The Cochrane Library, Issue 2, 2010. Oxford: Update Software.

2. Working Group of the Infectious Diseases Society of Southern Africa. Updated guideline for the management of upper respiratory tract infections in South Africa: 2008. South Afr J Epidemiol Infect. 2009;24(1):1-9.

3. Spinks A, Glasziou PP, Del Mar CB. Antibiotics for sore throat. [Cochrane review). In: The Cochrane Library, Issue 9, 2011. Oxford: Update Software.

4. Sanders S, Glasziou PP, Del Mar CB, Rovers MM. Antibiotics for acute otitis media in children. [Cochrane review]. In: The Cochrane Library, Issue 9, 2010. Oxford: Update Software.

5. Dohar J, Giles W, Roland P, Bikhazi N, et al. Topical ciprofloxacin/dexamethasone superior to oral amoxicillin/clavulanic acid in acute otitis media with otorrhea through tympanostomy tubes. Pediatrics. 2006;118(3):e561-e569.

6. Ahovuo-Saloranta A, Rautakorpi UM, Borisenko OV, et al. Antibiotics for acute maxillary sinusitis. [Cochrane review]. In: The Cochrane Library, Issue 3, 2011. Oxford: Update Software.

7. Barlan IB, Erkan E, Bakir M, et al. Intranasal budesonide spray as an adjunct to oral antibiotic therapy for acute sinusitis in children. Ann Allergy Asthma Immunol. 1997;78(6):598-601.

8. Yilmaz G, Varan B, Yilmaz T, Guarakan B. Intranasal budesonide spray as an adjunct to oral antibiotic therapy for acute sinusitiis in children. Eur Arch Otorhinolaryngol. 2000;257(5):256-259.

9. Meltzer EO, Charous BL, Busse WW, et al. Added relief in the treatment of acute recurrent sinusitis with adjunctive mometasone furoate nasal spray. The Nasonex Sinusitis Group. J Allergy Clin Immunol. 2000;106(4):630-637.

10. Meltzer EO, Bachert C, Staudinger H. Treating acute rhinosinusitis: comparing efficacy and safety of mometasone furoate nasal spray, amoxicillin, and placebo. J Allergy Clin Immunol. 2005;116(6):1289-1295.

11. Steele RW. Rhinosinusitis in children. Curr Allergy Asthma Rep. 2006;6(6):508-512. 